\title{
An Overview of Alpha Synuclein Protein and Its Role in Parkinson's disease
}

\section{Zeynep Bengisu Kaya', [MD] ORCID: 0000-0001-9713-8732}

Pergin Atilla', [MD]

ORCID: 0000-0001-5132-0002

\section{w ABSTRACT Con}

Parkinson's disease is the most common age-related motor movement disorder. Pathological changes in Parkinson's disease are the loss of melanin-containing dopaminergic neurons and the detection of inclusion bodies in the cells, which contain alpha-synuclein and ubiquitinated proteins, called as Lewy bodies. In this review; the structure of Lewy bodies, structural features and intracellular localization of a-synuclein protein, intracellular functions and intercellular spread of a-synuclein protein are discussed. The physiological and pathologic features of a-synuclein protein are reviewed based mostly upon review of the literature. $a$-synuclein has significant functions especially at central nervous system. $a$-synuclein is a protein that can be found in various areas within the cell, particularly in the presynaptic axon terminals. Under pathologic conditions, cellular accumulation of misfolded a-synuclein oligomers and aggregates are observed in a group of neurodegenerative diseases called synucleinopathies. The mechanisms of how a-synuclein protein takes part in the neurodegeneration process and physiologic roles of the protein have not been fully elucidated yet. It's important to unravel the secrets of this protein and understand its behaviours in order to improve existing treatment protocols and also to develop new and more effective treatments for Parkinson's Disease.

Keywords: Parkinson's disease, alpha-synuclein, neurodegeneration, neuroinflammation, neurotoxicity

https://doi.org/10.32552/2021.ActaMedica.510

Received: 16 September 2020, Accepted: 14 October 2020

Published online: 5 February 2021

\section{INTRODUCTION}

\section{Parkinson's Disease}

Parkinson's disease (PD) is the most common agerelated motor movement disorder ans second most common neurodegenerative disease after Alzheimer's disease. The prevalence of the disease is $2-3$ per thousand in the population and $1 \%$ in the age of 55 years. It is a progressive neurodegenerative disorder in which many systems are affected. Both non-motor and motor symptoms occur during the progress of the disease. Generally, patients have some non-motor symptoms at early and silent stages of the disease. Motor symptoms usually occur after $80 \%$ loss of dopaminergic neurons at substantia nigra pars compacta. The most common motor symptoms related with PD are; bradykinesia, tremor, rigidity and postural instability $[1,2]$.

The studies have shown that, there are various pathological mechanisms underlying Parkinson's disease. The most emphasized ones of them so far are; mitochondrial disorder, ubiquitin proteasome system dysfunction, change in calcium homeostasis and increased oxidative stress [3]. Although there is no single pathway describing the underlying mechanism of the disease, the main mechanism responsible for cellular pathologies is thought to be the aggregation of $a$-syn protein and subsequent mitochondrial dysfunction. Another important mechanism is neuroinflammation, which is getting 
popular each day and there are lots of studies ongoing in this field [4].

Since there is no definitive cure for PD nor other neurodegenerative disorders, it is crucial to enlighten cellular pathologies and neurodegeneration pathways to develop new treatments for efficient clinical practices.

\section{Lewy Bodies}

Fritz Jakob Heinrich Lewy (1885-1950) described the inclusion bodies in Parkinson's disease in 1912 5. Later, in 1919, Konstantin Nikolaevich Tretiakoff (1892-1956) named these structures as Lewy bodies. Lewy also identified inclusion bodies in neuron extensions (axons) as well as in the cell body; which are known as Lewy neurites [6]. So far, Lewy bodies are thought to be indicators of neuronal degeneration $[6,7]$.

Looking to the structure of Lewy bodies, there is a complex structure containing many different molecules. We are still not completely sure how these structures are shaped and whether they are the definitive cause of cell death. With the help of new laboratory methods, the structure of Lewy bodies is being illuminated more and more every day and new molecules are being defined. According to the data obtained so far, it contains more than 90 molecules, mostly composed of a-synuclein (a-syn) protein. In addition, the products of PD-related genes (DJ-1, LRRK2, parkin and PINK1), mitochondrial-related proteins and the molecules are associated with ubiquitin proteasome system (UPS) [7]. A new study shows that besides these proteins, Lewy bodies have some lipid content too. According to the research; in Lewy bodies there are some membrane residues, including vesicular structures and membranes of dysmorphic organelles. These results suggest that there might be a protein-lipid mixture in Lewy bodies [8].

Previous researches showed that, Lewy bodies first appear as pale, slightly eosinophilic accumulations in the cells and then these structures are become Lewy bodies $[6,7]$. Further studies with electron microscopy, it was observed that Lewy bodies and Lewy neurites contain 200-600 nm long and 5-10 $\mathrm{nm}$ wide, non-branched fibrillar a-syn protein [6]. Two types of Lewy bodies have been identified: brain stem type (classical type) and cortical type $[6,7]$. In brightfield microscopy studies, sections stained with haematoxylin and eosin staining, the brainstem Lewy bodies are observed as eosinophilic masses located intracytoplasmic, single or multiple, spherical or prolonged, have dense nucleus and peripheral ring. The cortical type is not as well defined as the brain stem type. The cortical type was observed different from brainstem type in some ways; a halo was not seen, and thread-like Lewy neurites were found in the axons and dendrites of the affected neurons. The cortical Lewy bodies are also eosinophilic structures with irregular in shape like brainstem Lewy bodies [7]. Brain stem type and cortical type Lewy bodies have strong immunostaining with ubiquitin and phosphorylated a-syn $[6,7]$.

Lewy bodies are widely seen in central nervous system (CNS). Studies show that Lewy bodies are seen in olfactory bulbus [9], hypothalamus [10], posterior lobe of pituitary gland [11], substantia nigra, locus coeruleus, dorsal raphe nucleus, dorsal vagal nucleus [12], cerebellum [13] and medulla spinalis $[14,15]$. In addition, they can be located in amygdaloidal nucleus and cerebral cortex neurons, especially in the deep layers of limbic system ( $V$ and VI) $[16,17]$. Similar inclusions were found in many areas of the peripheral nervous system (PSS). In PSS they are observed in sympathetic ganglion [18], enteric nervous system (Meissner and Auerbach plexuses) [19-22], heart [23], pelvic organs [24], adrenal medulla $[24,25]$, submandibular gland $[26,27]$ and skin $[28,29]$.

\section{Synucleins and Alpha Synuclein}

Synucleins, are small and soluble proteins located especially in nervous tissue and in some tumors. Unlike many other proteins, they found only in vertebrates $[30,31]$. Three members of synuclein family have been identified so far: $\alpha-, \beta$ - and $\gamma$ - synuclein [30-32]. Synucleins have gained importance after the linkage found between a-syn protein and Parkinson's disease, both geneticallyand neuropathologically. While a-syn has been shown to be associated with various neurodegenerative diseases such as Lewy body dementia, Multiple system atrophy (MSA), Alzheimer's disease (AD), Parkinson's disease (PD); $Y$-syn is found to be related with especially some cancers, also some neurodegenerative diseases and eye pathologies $[32,33]$. It is thought that $\beta$-syn acts as an antagonist to $\alpha$-syn and its function is preventing misfolding and intracellular accumulation of a-syn in the cell [30,31]. 
The synuclein proteins have three regions with different contents. These are; the amino-terminal region ( $\mathrm{N}$-terminal), the central region and the carboxyl-terminal region (C-terminal) [31,34]. The amino terminal region ( $\mathrm{N}$-terminus) is the part that binds with acidic lipids, and is responsible for the formation of the a-helix structure during the binding to the membrane phospholipids. This portion is conserved between species $[31,34,35]$. The central region is responsible for the conformational change required to form fibrils ( $\beta$-sheet structure) $[34,36]$. The carboxyl terminal region (terminal $C$ ) has a high negative charge and it is variable between species. It is also the binding region for $\mathrm{Ca}^{2+}, \mathrm{Cu}^{2+}$ and other cations $[34,36]$.

The synucleins exhibit conformational changes with temperature rise or acidic $\mathrm{pH}$ while they are unfolded in the cell at physiological conditions and at neutral $\mathrm{pH}$. The most common conformational change is fibrillation and it is mostly seen in a-syn. While it is not seen in $\beta$-syn, it is seen at higher concentrations in $\gamma$-syn $[31,34]$.

\section{Alpha Synuclein}

\section{Structure and Location of Alpha Synuclein Protein}

Human a -syn protein is a 140 amino acid and normally an unfolded protein [34,37] encoded by the SNCA gene. The SNCA gene is located at the chromosome 4q21 [31,34].

a-syn protein has been shown to be found mostly in human brain, especially in the neocortex, hippocampus, substantia nigra (SN), thalamus and cerebellum [38]. The heart, muscle and other tissues present the protein in small amounts [33]. It has shown that a-syn protein can accumulate in neurons at various locations such as; cytoplasm, nucleus, mitochondria, presynaptic terminals, synapses (Figure 1) and also extracellular areas in central, autonomic and peripheral nervous system [39-41]. The a-syn protein is also found in the cerebrospinal fluid in the central nervous system which means it has ability to cross the bloodbrain barrier and switch between cerebrospinal fluid and peripheral blood [42]. In addition to this locations, $a$-syn protein is present in platelets and lymphocytes [41].

It has been shown that a-syn can be present in many conformations under in vitro conditions.
Under normal conditions, when it first synthesized in the cell, it is in the form as unfolded monomer [37,43]. A lot of studies about Parkinson's disease showed that, a-syn (dimer, oligomer, protofibril and fibril) proteins can be found in different conformations in the cells $[37,44,45]$. Normally, levels of these different conformations of a-syn protein in the cell, are thought to be in a certain balance. It is known that the a-syn protein has various functions within the cell under normal conditions $[34,37,43]$. Conformational changes at the structure of the protein are important for the formation of Lewy bodies and also physiological functions of the protein. The majority of Lewy bodies are consist of the a-syn protein in the fibrillar form $[34,37,43]$. The a-syn protein has also been shown to induce neurotoxicity under in vitro conditions, when it is partially folded or has oligomeric structure $[34,37,43,44]$. Oligomers are in $\beta$-sheet form, are much smaller than aggregates and their sizes are variable. The oligomers might be the transition form between the monomer and fibrillar forms of the a-syn protein; however, if the protein remains the oligomeric form in the cells it is known that it causes cytotoxicity $[37,44]$. Although the mechanisms of toxicity for the a-syn protein are still not fully enlightened, so far the most emphasized mechanism is they might cause membrane damages [46]. In vitro and in vivo studies have shown that the loss of dopaminergic neurons is increased related to the oligomeric a-syn overexpression, that can cause pores on membranes, followed by increased calcium $\left(\mathrm{Ca}^{2+}\right)$ permeability and as a result cytotoxicity and cell death are elevated $[43,45,47]$. The pathophysiology of a-syn misfolding includes endoplasmic reticulum stress, oxidative stress, impaired $\mathrm{Ca}^{2+}$ balance and neuroinflammation [45].

\section{Post-Translational Modifications of Alpha Synuclein Protein}

a-syn protein has various post-translational modifications, after synthesized. With these modifications; functions of the protein are regulated, the protein is directed to different intracellular areas, and as a result of some modifications the pathological forms of the protein occur within the cell [48]. Analysis of Lewy bodies revealed, there are different forms of modified a-syn proteins in these inclusion bodies. The most common post-translational modifications are; 

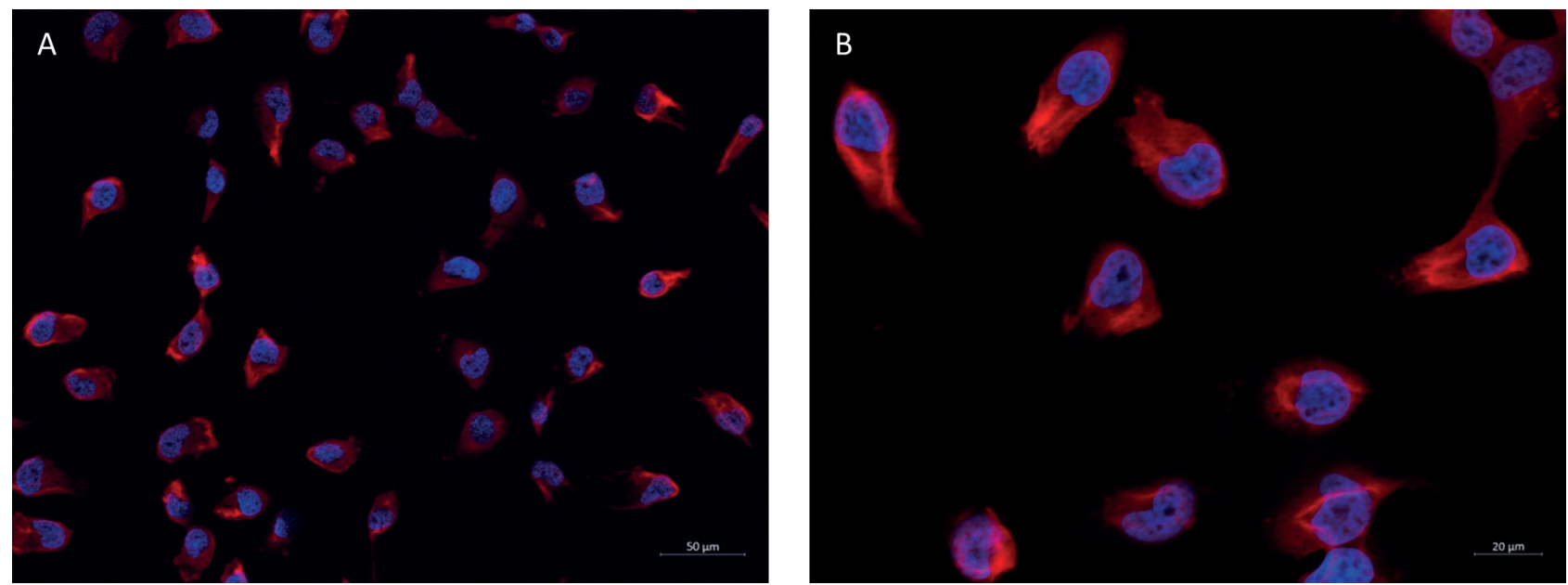

Figure 1. a-syn immunofluorescent labeling of a-syn overexpressing $\mathrm{H} 4$ human neuroglioma cells. Blue (DAPI, Vectasheild Mounting Medium with DAPI H-1200, Vector Laboratories); Nuclei of the cells. Red HRP anti-a-Synuclein antibody, Biolegend); a-syn protein (Magnifications: A, x20 and B, x40) (Unpublished data; Kaya et al. 2020)

phosphorylation, nitration and ubiquitination. Other post-translational modifications that are observed are; glycosylation, enzymatic crosslinking, methionine oxidation, and proteolytic cleavage from the C-terminus [34,48].

Phosphorylated a-syn protein is closely related to the pathogenesis of Parkinson's disease. The C-terminal of the protein is additionally negative charged. It has been shown that, phosphorylated a-syn is located especially at the mitochondria in the cell and it binds to the inner membrane of the mitochondria, leads to the dysfunction of the electron transport chain (ETC) complex I. Approximately $90 \%$ of the insoluble a-syn proteins are in phosphorylated form $[40,49]$.

Nitration is another post-translational modification that has an important role in the pathogenesis of neurodegenerative diseases. There are studies that show the cytoplasmic accumulation of nitrated a-syn protein in brain tissues is related to synucleinopathies. It was observed that nitrated $a$-syn protein causes amorphous protein aggregates in the cells $[36,40]$.

Ubiquitination is one of the important posttranslational mechanisms involved in the pathogenesis of PD. Looking at the structure of Lewy bodies, the a-syn protein there, is mostly in ubiquitinated form. Ubiquitin is a 76 amino acid (aa) protein that binds to other proteins with three sequential enzymatic activities. The linkage usually occurs between the carboxyl group (COO-) of glycine, the last amino acid of ubiquitin, and the amino group $(\mathrm{NH}+3)$ in the lysine residue of the substrate protein $[34,50]$. Three enzymatic steps of ubiquitination are; activation (ubiquitin activation enzymes-E1), conjugation (ubiquitin conjugation enzymes-E2) and ligation (ubiquitin ligases-E3) [50].

Up to now, more than ten protein-encoding genes have been identified in Parkinson's disease. In these which related to UPS are; Parkin, CHIP, TRAF6 and UCHL1 mutations. Parkin, CHIP and TRAF6 are E3 enzymes, and UCHL1 is a deubiqutination enzyme that separates ubiquitin from the substrate protein [51].

\section{Other Proteins that Alpha Synuclein Protein Interacts in the Cell}

a-syn protein can interact with various other proteins in Lewy bodies or in the cell. Different protein interactions can interfere with protein biogenesis and lead to neurodegenerative disorders. As a result, these interactions between other proteins and a-syn protein may trigger misfolding and aggregation of a-syn, and finally speeds up the disease progression. Protein interactions can occur on both co-translational and post-translational levels [52].

The most emphasized ones of these proteins are; Synphilin, Tubulin, Cysteine-string protein- a (CSP a), Rab, Agrin, histone proteins, chaperone proteins, 14-3-3 protein and Tau protein [38].

Synphilin, is a protein located in the Lewy bodies or in the cytoplasm that interacts with a-syn. Although early studies have suggested that this protein may increase the tendency to form aggregates and 
inclusion bodies of a-syn protein, on the contrary recent studies have shown that this protein is neuroprotective $[53,54]$.

Tubulin is one of the proteins involved in cytoskeleton. Studies have shown that tubulin can increase the formation of a-syn fibrils by initiating polymerization of a-syn. Besides, some epigenetic factors (such as drugs, chemicals, environmental toxins, food additives) can enhance a-syn fibrillation via tubulin [55]. In addition, it has been observed that the microtubule formation in the cell is inhibited by the interaction of a-syn with tubulin [56].

CSP- $\boldsymbol{a}$ is a synaptic vesicular protein. In recent years, it has been shown to be neuroprotective in in vivo and in vitro studies. It is thought that it takes a role in maintaining synaptic function and through this it has a neuroprotective effect $[57,58]$.

Rab proteins (Rab GTPases) are a family of protein associated with the regulation of cell membrane dynamics and intracellular vesicular transport. Selectively, some Rab proteins (Rab3a, Rab5, Rab8, Rab7, Rab11a) bind with a-syn to protect cells from damage caused by a-syn mutation or overexpression [59]. Cells with mutant a-syn protein or containing fibrillar form of a-syn and accumulation of a-syn aggregates, have damaged axonal transport, and also have an irregularity in vesicle trafficking [60].

Agrin, is of a proteoglycan which has shown to be involved with a-syn in Lewy bodies and Lewy neurites in patients with PD. By binding with a-syn, it triggers conformational changes and causes $\beta$-sheet and protofibril structures to be formed in the cell $[61,62]$. Some studies and analyses have shown that agrin increases the insoluble a-syn in the cells and enhances fibril formation [63].

Histone proteins are located at the nucleus of the cell. Binding of the a-syn protein in the nucleus, increases the acetylation and aggregation of the a-syn. A recent study also demonstrates that histone-induced aggregates contain a-syn oligomers, protofibrils and mature fibrils, and can trigger additional aggregation. Finally, causes increased neurotoxicity [64].

Chaperones are assisting proteins that play a role in folding of the intracellular proteins properly and get their three-dimensional structures. a-syn interacts with various chaperones, particularly Hsp27, Hsp70, Hsp90, and can be located together with these proteins in Lewy bodies. Chaperones take part in protein aggregation, re-localization of a-synuclein to the mitochondria and inhibition of protein degradation [65].

14-3-3 proteins are proteins that have chaperone function, involved in regulating intracellular protein trafficking and arehighly expressed in nervous tissue cells. 14-3-3 interacts with the proteins mentioned in Parkinson's disease, particularly a-syn, parkin and LRRK2. Studies have shown that in Lewy bodies a-syn protein and 14-3-3 proteins are co-localized. In the literature, there are some claims that these proteins reduce the transmission of a-syn from cellto-cell. However, it has not been shown that there is a reduction in a-syn oligomerization or formation of intracellular aggregates [66].

Tau protein is known to be important in the pathogenesis of Alzheimer's disease, especially in the process of neurodegeneration. There are some studies indicate that accumulated a-syn protein in PD, interacts with Tau protein in the cell. Interaction of a-syn with Tau protein, initiates tau fibrillation. An another view is, the interaction of these proteins starts protein polymerization and then each other's transition to fibrillar form $[67,68]$.

\section{Intracellular Localizations of Alpha Synuclein Protein}

The a-syn protein is capable of binding with membrane lipids. Thus, it can make connections with cell membrane structures (mitochondria membrane, endoplasmic reticulum, golgi apparatus and nuclear membrane). The mitochondrial membrane affinity is thought to be higher among those structures. Cell toxicity is elevated by a-syn protein binding to cell membrane structures. Although the mechanisms of toxicity are not fully clear yet, common thought is due to membrane damage and increased calcium $\left(\mathrm{Ca}^{2+}\right)$ transmission through the cytoplasm $[69,70]$.

\section{Nucleus}

a-syn protein does not target the nucleus under physiological conditions. The translocation to the nucleus is triggered by monoubiquitination and increased oxidative stress. Following, neurotoxicity is elevated by the translocation of a-syn into the nucleus. Neurotoxicity and neuroinflammatory 
environment starts DNA fragmentation and some different cell death mechanisms, including apoptosis and necrosis, occur [70]. After entering the nucleus a-syn can interact with histone proteins. There are also some studies showing that it can alter the regulation of some gene expressions. a-syn also can bind directly to a single DNA chain that is transcriptionally active and does not contain histones, which means it can change the stability and conformation of DNA [71,72].

\section{Mitochondrion}

Mitochondria are the main regulators of energy metabolism and apoptotic pathways in the cell. Mitochondrial oxidative stress has a major role in the pathogenesis of neurodegenerative diseases. The main mechanism responsible for pathologies is the aggregation of the a-syn protein followed by loss of mitochondrial function [73].

The a-syn protein has the ability to bind with various molecules both located on the inner and outer membranes of mitochondria. It is well known that, a-syn binds with cardiolipin which is located on the inner membrane [35,74]. a-syn binding to cardiolipin is independent from membrane potential changes. Another mechanism defined for binding mitochondria membrane is, interacting with TOM 40, a channel located at the mitochondrial translocase of outer membrane (TOM) complex [74]. In addition to this, it is thought that a-syn can bind to TOM 20 too, again located on the mitochondrial membrane, and through this binding can inhibit the import of some necessary proteins to mitochondria [75]. In vivo and in vitro studies have shown that mitochondrial fragmentation occurs after a-syn binds to mitochondria. a-syn is also thought to enhance the communication between the endoplasmic reticulum (ER) and mitochondria and the transfer of calcium $\left(\mathrm{Ca}^{2+}\right)$ from $E R$ to mitochondria. a-syn may enhance the elevated levels of cellular reactive oxygen species (ROS) over its link with mitochondria. The mitochondrial enzyme complex of ETC I and III are the primary sites for the production of ROS. In particular, functions of ETC enzyme complex I might be changed related to a-syn protein $[73,74]$. ROS accumulation occurs in the cell due to structural changes at the mitochondrial membrane and loss of function of the ETC system. ROS increase leads to the oxidation of dopamine in the dopaminergic neurons [3]. Oxidized dopamine is a specific protein that causes mitochondrial damage and enhances the vulnerability of dopaminergic neurons [2,3]. Disruption of intracellular dopamine homeostasis also causes increase in ROS. As a result, mitochondrial dysfunction is triggered and increased intracellular oxidative stress occurs. Mitochondrial damage is further triggered by increased ROS in the cell as a result of mitochondrial dysfunction. This process, starts with an increase in intracellular oxidative stress, leads to the death of the cells by repeating these steps like a cycle $[3,76]$.

\section{Functions of Alpha Synuclein Protein}

It is well known that, a-syn is a protein that expressed in the cell under physiological conditions, yet all functions of this protein are not fully understood. The most important functions that have been shown so far are; reduction of apoptosis by suppression of protein kinase C (PKC) activity in dopaminergic neurons [77], prevention of unsaturated fatty acid oxidation by acting as an antioxidant [78], regulation of synaptic vesicle trafficking at presynaptic terminals [79], contributing to SNARE complex formation $[80,81]$, taking part at clatrin-dependent endocytosis [82], inhibition of Phospholipase D2 (PLD2) [83], taking part at neuronal differentiation.

Presynaptic terminals are important for the release of neurotransmitters and to ensure inter-neuronal communication. In particular, a-syn is thought to be helpful with the regulation of dopamine release in the substantia nigra, the brain region responsible for balance and movement control [84].

In addition to these functions, some studies have shown that, a-syn plays a role in the regulation of blood glucose levels [85].

\section{Translocation of Alpha Synuclein Protein to the Extracellular Area and Endocytosis by Other Cells}

It has shown with some studies that a-syn protein can pass from cell to cell. a-syn protein is covered by a vesicle in the cell and transported out of the cell by exocytosis $[3,86]$. a-syn can be released by some exocytosis mechanisms including exosome releasing, and autophagosome mediated exocytosis. There are also some studies that claims a-syn protein can pass through between the cells by a prion like manner $[87,88]$. 
a-syn protein is taken into cells from the extracellular space by endocytosis. The cells of central nervous system which are known that can take a-syn by endocytosis are, neurons and glia cells (microglia cells, astrocytes, oligodendrocytes) $[88,89]$. In a recent study, it is shown that, under in vitro conditions the protofibrillar form of the a-syn protein is taken by the other neurons from extracellular area via binding to LAG-3 (lymphocyteactivation gene 3 ) receptor. In the same study, the researchers haven't detected LAG-3 receptor at the membrane of astrocytes and microglia cells, thus, it is thought to be important for the uptake of protofibrillar form of a-syn protein into the neurons. In the same study, binding of a-syn protein to the LAG-3 receptor has also been shown to induce endocytosis of more a-syn protein inside the cells [86].

Another receptor involved with the endocytosis of a -syn protein is the toll-like receptor 2 (TLR2) receptor. The TLR2 receptor is present at neurons and glia cells and plays a role in the endocytosis of both the oligomer and the fibrillar form of a-syn [90]. Interestingly, in some studies, increased TLR2 protein levels are observed higher in neurons than in microglia cells. In microglia cells, by TLR2 activation inflammatory cytokines are expressed and released from the cells. Triggered inflammation results with increased neurotoxicity and accelerated cell degeneration [88,91]. Inflammatory cytokines, especially TNF- $a$ and IL$1 \beta$ increase with inflammation, while IL-2 and IL-6 are also detected [92]. TNF- $\alpha$ is known to strongly induce ROS production through mitochondria and also to induce apoptosis as an external apoptosis activator [92]. Similarly, when neuronal TLR2 is activated, there is an increase of inflammatory cytokine levels which leads an increase of oxidative stress and also accumulation of endogenous a-syn protein [90].

\section{CONCLUSION}

a-synuclein is an intracellular protein that has been shown to play a role in a group of neurodegenerative diseases called synucleinopathies. Lewy bodies are an important pathological structure in synucleinopathies, especially in Parkison's Disease. Although many studies about this protein have been done so far, most of the a-syn protein functions remain unclear. In various studies, it has been shown that a-syn protein can be found in different areas within the cell (nucleus, mitochondria, endoplasmic reticulum, cytoplasm, axon terminal). It is now well known that, a-syn is located especially at axon terminals, on the membrane of the synaptic vesicles and is strongly involved with the synapses. The misfolded and / or overexpressed a-syn protein has been shown to be toxic to the cell by forming oligomers and aggregates, and cause cell death through various pathways. The most common cell death pathways are apoptosis necrosis. In addition, recent studies have shown that some cytotoxic forms of a-syn protein can pass through the extracellular area and can be taken into the neurons and other glia cells by endocytosis. The details of the exocytosis and endocytosis are not fully elucidated yet; the further studies are going on about these pathways. Since a-syn has some important functions in the cells and also is related with neurodegenerative diseases, a complete understanding of the synthesis, folding, different forms and aggregations of this protein is crucial for developing new clinical treatments for the diseases that have no exact cure so far.

\section{CONFLICT Of INTEREST STATEMENT}

The authors declare they have no conflicts of interest. 
[1] Jellinger KA. Neuropathobiology of non-motor symptoms in Parkinson disease. Journal of Neural Transmission. 2015; 122(10): 1429-1440.

[2] Michel PP, Hirsch EC, Hunot S. Understanding dopaminergic cell death pathways in Parkinson disease. Neuron. 2016; 90(4): 675-691.

[3] Alberio T, Lopiano L, Fasano M. Cellular models to investigate biochemical pathways in Parkinson's disease. FEBS Journal. 2012; 279(7): 1146-1155.

[4] Kaur K, Gill JS, Bansal PK, et al. Neuroinflammation-A major cause for striatal dopaminergic degeneration in Parkinson's disease. Journal of the neurological sciences. 2017; 381: 308-314.

[5] Engelhardt E, Gomes MdM. Lewy and his inclusion bodies: Discovery and rejection. Dementia \& Neuropsychologia. 2017; 11(2): 198-201.

[6] Goedert M, Spillantini MG, Del Tredici K, et al. 100 years of Lewy pathology. Nature Reviews Neurology. 2013; 9(1): 13.

[7] Wakabayashi K, Tanji K, Odagiri S, et al. The Lewy body in Parkinson's disease and related neurodegenerative disorders. Molecular neurobiology. 2013; 47(2): 495-508.

[8] Shahmoradian SH, Lewis AJ, Genoud C, et al. Lewy pathology in Parkinson's disease consists of crowded organelles and lipid membranes. Nature neuroscience. 2019; 22(7): 1099-1109.

[9] Ubeda-Banon I, Saiz-Sanchez D, de la Rosa-Prieto $C$, et al. a-Synucleinopathy in the human olfactory system in Parkinson's disease: involvement of calciumbinding protein-and substance P-positive cells. Acta neuropathologica. 2010; 119(6): 723-735.

[10] Langston JW, Forno LS. The hypothalamus in Parkinson disease. Annals of Neurology: Official Journal of the American Neurological Association and the Child Neurology Society. 1978; 3(2): 129-133.

[11] Homma T, Mochizuki Y, Mizutani T. Phosphorylated asynuclein immunoreactivity in the posterior pituitary lobe. Neuropathology. 2012; 32(4): 385-389.

[12] Braak H, Rueb U, Sandmann-Keil D, et al. Parkinson's disease: affection of brain stem nuclei controlling premotor and motor neurons of the somatomotor system. Acta neuropathologica. 2000; 99(5): 489-495.

[13] Mori F, Piao Y-S, Hayashi S, et al. a-Synuclein accumulates in Purkinje cells in Lewy body disease but not in multiple system atrophy. Journal of Neuropathology \& Experimental Neurology. 2003;62(8):812-819.

[14] Braak H, Sastre M, Bohl JR, de Vos RA, et al. Parkinson's disease: lesions in dorsal horn layer I, involvement of parasympathetic and sympathetic pre-and postganglionic neurons. Acta neuropathologica. 2007; 113(4): 421-429.

[15] Tamura T, Yoshida M, Hashizume $Y$, et al. Lewy bodyrelated a-synucleinopathy in the spinal cord of cases with incidental Lewy body disease. Neuropathology. 2012; 32(1): 13-22.
[16] Braak H, Braak E, Yilmazer D, et al. Amygdala pathology in Parkinson's disease. Acta neuropathologica. 1994; 88(6): 493-500.

[17] Wakabayashi K, Hansen LA, Masliah E. Cortical Lewy bodycontaining neurons are pyramidal cells: laser confocal imaging of double-immunolabeled sections with antiubiquitin and SMI32. Acta neuropathologica. 1995; 89(5): 404-408.

[18] Forno LS, Norville RL. Ultrastructure of Lewy bodies in the stellate ganglion. Acta neuropathologica. 1976; 34(3): 183197.

[19] Braak H, de Vos RA, Bohl J, Del Tredici K. Gastric a-synuclein immunoreactive inclusions in Meissner's and Auerbach's plexuses in cases staged for Parkinson's disease-related brain pathology. Neuroscience letters. 2006; 396(1): 67-72.

[20] Kuo Y-M, Li Z, Jiao Y, et al. Extensive enteric nervous system abnormalities in mice transgenic for artificial chromosomes containing Parkinson disease-associated a-synuclein gene mutations precede central nervous system changes. Human molecular genetics. 2010; 19(9): 1633-1650.

[21] Mrabet S, Ben Ali N, Achouri A, et al. Gastrointestinal dysfunction and neuropathologic correlations in Parkinson disease. Journal of clinical gastroenterology. 2016; 50(9): e85-e90.

[22] Stokholm MG, Danielsen EH, Hamilton-Dutoit SJ, et al. Pathological a-synuclein in gastrointestinal tissues from prodromal $P$ arkinson disease patients. Annals of neurology. 2016; 79(6): 940-949.

[23] Orimo S, Uchihara T, Nakamura A, et al. Axonal a-synuclein aggregates herald centripetal degeneration of cardiac sympathetic nerve in Parkinson's disease. Brain. 2008; 131(3): 642-650.

[24] Minguez-Castellanos A, Chamorro C, Escamilla-Sevilla F, et al. Do a-synuclein aggregates in autonomic plexuses predate Lewy body disorders?: a cohort study. Neurology. 2007; 68(23): 2012-2018.

[25] Fumimura $Y$, Ikemura $M$, Saito $Y$, et al. Analysis of the adrenal gland is useful for evaluating pathology of the peripheral autonomic nervous system in Lewy body disease. Journal of neuropathology and experimental neurology. 2007; 66(5): 354-362.

[26] Del Tredici K, Hawkes CH, Ghebremedhin E, et al. Lewy pathology in the submandibular gland of individuals with incidental Lewy body disease and sporadic Parkinson's disease. Acta neuropathologica. 2010; 119(6): 703-713.

[27] Vilas D, Iranzo A, Tolosa E, et al. Assessment of a-synuclein in submandibular glands of patients with idiopathic rapideye-movement sleep behaviour disorder: a case-control study. The Lancet Neurology. 2016; 15(7): 708-718.

[28] Miki Y, Tomiyama M, Ueno T, et al. Clinical availability of skin biopsy in the diagnosis of Parkinson's disease. Neuroscience letters. 2010; 469(3): 357-359. 
[29] Donadio V, Incensi A, Leta V, et al. Skin nerve a-synuclein deposits A biomarker for idiopathic Parkinson disease. Neurology. 2014; 82(15): 1362-1369.

[30] George JM. The synucleins. Genome biology. 2001; 3(1): reviews3002. 3001.

[31] Surguchov A. Intracellular dynamics of synucleins:"here, there and everywhere". In: International review of cell and molecular biology. Vol 320. Elsevier; 2015: 103-169.

[32] Lavedan C. The synuclein family. Genome research. 1998; 8(9): 871-880.

[33] Clayton DF, George JM. The synucleins: a family of proteins involved in synaptic function, plasticity, neurodegeneration and disease. Trends in neurosciences. 1998; 21 (6): 249-254.

[34] Kallman M. Synthesis and Evaluation of a-Synuclein (6-36). 2013.

[35] Shen J, Du T, Wang X, et al. a-Synuclein amino terminus regulates mitochondrial membrane permeability. Brain research. 2014; 1591: 14-26.

[36] Liu Y, Qiang M, Wei Y, et al. A novel molecular mechanism for nitrated a-synuclein-induced cell death. Journal of molecular cell biology. 2011; 3(4): 239-249.

[37] Dettmer U, Selkoe D, Bartels T. New insights into cellular a-synuclein homeostasis in health and disease. Current opinion in neurobiology. 2016; 36: 15-22.

[38] Emamzadeh FN. Alpha-synuclein structure, functions, and interactions. Journal of research in medical sciences: the official journal of Isfahan University of Medical Sciences. 2016; 21

[39] Galvin JE, Schuck TM, Lee VM-Y, et al. Differential expression and distribution of $\alpha-, \beta-$, and $\gamma$-synuclein in the developing human substantia nigra. Experimental neurology. 2001; 168(2): 347-355.

[40] Surguchov A. Molecular and cellular biology of synucleins. International review of cell and molecular biology. 2008; 270: 225-317.

[41] Nam M-K, Han J-H, Jang J-Y, et al. A novel link between the conformations, exposure of specific epitopes, and subcellular localization of a-synuclein. Biochimica et Biophysica Acta (BBA)-General Subjects. 2015; 1850(12): 2497-2505.

[42] Sui Y-T, Bullock KM, Erickson MA, Zet al.. Alpha synuclein is transported into and out of the brain by the blood-brain barrier. Peptides. 2014; 62: 197-202.

[43] Marmolino D, Foerch P, Atienzar F, et al. Alpha synuclein dimers and oligomers are increased in overexpressing conditions in vitro and in vivo. Molecular and Cellular Neuroscience. 2016; 71: 92-101.

[44] DeMaagd G, Philip A. Parkinson's Disease and Its Management: Part 1: Disease Entity, Risk Factors, Pathophysiology, Clinical Presentation, and Diagnosis. Pharmacy and Therapeutics. 2015; 40(8): 504.

[45] Luna E, Luk KC. Bent out of shape: a-Synuclein misfolding and the convergence of pathogenic pathways in Parkinson's disease. FEBS letters. 2015; 589(24): 3749-3759.

[46] Surguchev A, Surguchov A. Effect of a-synuclein on membrane permeability and synaptic transmission: a clue to neurodegeneration? Journal of neurochemistry. 2015; 132(6): 619-621.
[47] Winner B, Jappelli R, Maji SK, et al. In vivo demonstration that $a$-synuclein oligomers are toxic. Proceedings of the National Academy of Sciences. 2011; 108(10): 4194-4199.

[48] Oueslati A, Fournier M, Lashuel HA. Role of posttranslational modifications in modulating the structure, function and toxicity of a-synuclein: implications for Parkinson's disease pathogenesis and therapies. In: Progress in brain research. Vol 183. Elsevier; 2010: 115-145.

[49] Liu C, Fei E, Jia N, et al. Assembly of lysine 63-linked ubiquitin conjugates by phosphorylated a-synuclein implies Lewy body biogenesis. Journal of Biological Chemistry. 2007; 282(19): 14558-14566.

[50] McKinnon C, Tabrizi SJ. The ubiquitin-proteasome system in neurodegeneration. Antioxidants \& redox signaling. 2014; 21(17): 2302-2321.

[51] Zheng Q, Huang T, Zhang L, et al. Dysregulation of ubiquitin-proteasome system in neurodegenerative diseases. Frontiers in aging neuroscience. 2016; 8: 303.

[52] Hernandez SM, Tikhonova EB, Karamyshev AL. ProteinProtein Interactions in Alpha-Synuclein Biogenesis: New Potential Targets in Parkinson's Disease. Frontiers in Aging Neuroscience. 2020; 12: 72.

[53] Liu J, Li T, Thomas JM, et al. Synphilin-1 attenuates mutant LRRK2-induced neurodegeneration in Parkinson's disease models. Human molecular genetics. 2016; 25(4): 672-680.

[54] Shishido T, Nagano Y, Araki M, et al. Synphilin-1 has neuroprotective effects on MPP+-induced Parkinson's disease model cells by inhibiting ROS production and apoptosis. Neuroscience letters. 2019; 690: 145-150.

[55] Alim MA, Hossain MS, Arima K, et al. Tubulin seeds a-synuclein fibril formation. Journal of Biological Chemistry. 2002; 277(3): 2112-2117.

[56] Zhou R, Huang Y, Li X, et al. Molecular interaction of a-synuclein with tubulin influences on the polymerization of microtubule in vitro and structure of microtubule in cells. Molecular biology reports. 2010; 37(7): 3183-3192.

[57] Chandra S, Gallardo G, Fernández-Chacón R,et al. a-Synuclein cooperates with $\mathrm{CSPa}$ in preventing neurodegeneration. Cell. 2005; 123(3): 383-396.

[58] Burgoyne RD, Morgan A. Cysteine string protein (CSP) and its role in preventing neurodegeneration. Paper presented at: Seminars in cell \& developmental biology2015.

[59] Shi M-m, Shi C-h, Xu Y-m. Rab GTPases: the key players in the molecular pathway of Parkinson's disease. Frontiers in cellular neuroscience. 2017; 11: 81.

[60] Volpicelli-Daley LA. Effects of a-synuclein on axonal transport. Neurobiology of disease. 2017; 105: 321-327.

[61] Liu I-H, Uversky VN, Munishkina LA, et al. Agrin binds a-synuclein and modulates a-synuclein fibrillation. Glycobiology. 2005; 15(12): 1320-1331.

[62] Uversky VN, Eliezer D. Biophysics of Parkinson's disease: structure and aggregation of a-synuclein. Current Protein and Peptide Science. 2009; 10(5): 483-499.

[63] Candelise N, Schmitz $M$, Thüne $K$, et al. Effect of the micro-environment on a-synuclein conversion and implication in seeded conversion assays. Translational Neurodegeneration. 2020; 9(1): 1-16. 
[64] Jiang $P$, Gan $M$, Yen S-H, et al. Histones facilitate a-synuclein aggregation during neuronal apoptosis. Acta neuropathologica. 2017; 133(4): 547-558.

[65] Burmann BM, Gerez JA, Matečko-Burmann I, et al. Regulation of a-synuclein by chaperones in mammalian cells. Nature. 2020; 577(7788): 127-132.

[66] Wang B, Underwood R, Kamath A, et al. 14-3-3 Proteins Reduce Cell-to-Cell Transfer and Propagation of Pathogenic a-Synuclein. Journal of Neuroscience. 2018; 38(38): 8211-8232.

[67] Ishizawa T, Mattila P, Davies P, et al. Colocalization of tau and alpha-synuclein epitopes in Lewy bodies. Journal of Neuropathology \& Experimental Neurology. 2003; 62(4): 389-397.

[68] Moussaud S, Jones DR, Moussaud-Lamodière $E L$, et al. Alpha-synuclein and tau: teammates in neurodegeneration? Molecular neurodegeneration. 2014; 9(1): 43.

[69] Fusco G, Chen SW, Williamson PT, et al. Structural basis of membrane disruption and cellular toxicity by a-synuclein oligomers. Science. 2017; 358(6369): 1440-1443.

[70] Burré J, Sharma M, Südhof TC. Cell biology and pathophysiology of a-synuclein. Cold Spring Harbor perspectives in medicine. 2018; 8(3): a024091.

[71] Hegde ML, Rao K. DNA induces folding in a-synuclein: understanding the mechanism using chaperone property of osmolytes. Archives of biochemistry and biophysics. 2007; 464(1): 57-69.

[72] Vasudevaraju P, Guerrero E, Hegde ML, et al. New evidence on a-synuclein and Tau binding to conformation and sequence specific GC* rich DNA: relevance to neurological disorders. Journal of pharmacy \& bioallied sciences. 2012; 4(2): 112

[73] Ni H-M, Williams JA, Ding W-X. Mitochondrial dynamics and mitochondrial quality control. Redox biology. 2015; 4: 6-13.

[74] Nakamura K. a-Synuclein and mitochondria: partners in crime? Neurotherapeutics. 2013; 10(3): 391-399.

[75] Di Maio R, Barrett PJ, Hoffman EK, et al. a-Synuclein binds to TOM20 and inhibits mitochondrial protein import in Parkinson's disease. Science translational medicine. 2016; 8(342): 342ra78.

[76] Exner N, Lutz AK, Haass C, et al. Mitochondrial dysfunction in Parkinson's disease: molecular mechanisms and pathophysiological consequences. The EMBO journal. 2012; 31(14): 3038-3062.

[77] Jin H, Kanthasamy A, Ghosh A, et al. a-Synuclein negatively regulates protein kinase $C \delta$ expression to suppress apoptosis in dopaminergic neurons by reducing p300 histone acetyltransferase activity. Journal of Neuroscience. 2011; 31(6): 2035-2051.
[78] Hashimoto M, Hsu LJ, Rockenstein E, Tet al. a-Synuclein protects against oxidative stress via inactivation of the c-Jun $\mathrm{N}$-terminal kinase stress-signaling pathway in neuronal cells. Journal of Biological Chemistry. 2002; 277(13): 11465-11472.

[79] Oaks AW, Sidhu A. Parallel mechanisms for direct and indirect membrane protein trafficking by synucleins. Communicative \& integrative biology. 2013; 6(6): e26794.

[80] Südhof TC. The synaptic vesicle cycle. Annu Rev Neurosci. 2004; 27: 509-547.

[81] Rizo J, Südhof TC. The membrane fusion enigma: SNAREs, Sec1/Munc18 proteins, and their accomplices-guilty as charged? Annual review of cell and developmental biology. 2012; 28: 279-308.

[82] Vargas KJ, Makani S, Davis T, et al. Synucleins regulate the kinetics of synaptic vesicle endocytosis. Journal of Neuroscience. 2014; 34(28): 9364-9376.

[83] Gorbatyuk OS, LiS, Nguyen FN, etal. a-Synuclein expression in rat substantia nigra suppresses phospholipase D2 toxicity and nigral neurodegeneration. Molecular Therapy. 2010; 18(10): 1758-1768.

[84] Venda LL, Cragg SJ, Buchman VL, et al. a-Synuclein and dopamine at the crossroads of Parkinson's disease. Trends in neurosciences. 2010; 33(12): 559-568.

[85] Bendor JT, Logan TP, Edwards RH. The function of a-synuclein. Neuron. 2013; 79(6): 1044-1066.

[86] Mao X, Ou MT, Karuppagounder SS, et al. Pathological a-synuclein transmission initiated by binding lymphocyteactivation gene 3. Science. 2016; 353(6307): aah3374.

[87] Masuda-Suzukake M, Nonaka T, Hosokawa M, et al. Prionlike spreading of pathological a-synuclein in brain. Brain. 2013; 136(4): 1128-1138.

[88] Chistiakov DA, Chistiakov AA. a-Synuclein-carrying extracellular vesicles in Parkinson's disease: deadly transmitters. Acta Neurologica Belgica. 2017; 117(1): 4351.

[89] Codolo G, Plotegher N, Pozzobon T, et al. Triggering of Inflammasome by Aggregated a-Synuclein, an Inflammatory Response in Synucleinopathies. PloS one. 2013; 8(1): e55375.

[90] Dzamko N, Gysbers A, Perera G, et al. Toll-like receptor 2 is increased in neurons in Parkinson's disease brain and may contribute to alpha-synuclein pathology. Acta neuropathologica. 2017; 133(2): 303-319.

[91] Béraud D, Hathaway HA, Trecki J, et al. Microglial activation and antioxidant responses induced by the Parkinson's disease protein a-synuclein. Journal of Neuroimmune Pharmacology. 2013; 8(1): 94-117.

[92] Prajapati P, Sripada L, Singh K, et al. TNF-a regulates miRNA targeting mitochondrial complex-l and induces cell death in dopaminergic cells. Biochimica et Biophysica Acta (BBA)-Molecular Basis of Disease. 2015; 1852(3): 451-461. 